\title{
Association Between von Willebrand Factor (vWF) Gene Polymorphism and Coronary Heart Disease in Gaza Strip
}

\author{
Lamia'a Sobhi Saqer*, Mervat Jamal Kassab, Ansam Khalid Alshehri, Olfat M. Breaka \\ Medical Sciences Department, University College of Science and Technology, Gaza Strip, Palestine
}

Email address:

Lamiaa1912@yahoo.com (Lamia'a S. S.)

${ }^{*}$ Corresponding author

\section{To cite this article:}

Lamia'a Sobhi Saqer, Mervat Jamal Kassab, Ansam Khalid Alshehri, Olfat M. Breaka. Association Between von Willebrand Factor ( $v W F)$ Gene Polymorphism and Coronary Heart Disease in Gaza Strip. American Journal of Life Sciences. Vol. 4, No. 2, 2016, pp. 51-59. doi: 10.11648/j.ajls.20160402.16

Received: April 14, 2016; Accepted: April 25, 2016; Published: May 12, 2016

\begin{abstract}
The von Willebrand Factor $(v W F)$ gene located on Chromosome 12 spans $\sim 180$ kilobases with 52 exons. Changes in the $v W F$ gene could alter VWF biosynthesis, secretion, clearance, and adhesion activity. Single nucleotide polymorphisms (SNPs) in exons, $5^{\prime}$ regulatory region, and introns are also reported to influence levels of vWF in healthy subjects. Some of these vWF SNPs are associated with an elevated risk for thrombosis and may be causally associated with coronary heart disease. The objective of this work was to detect the association between-1185A/G $v W F$ gene polymorphism and CHD in Gaza strip. We conducted case-control study included 126 samples comprised 85 CHD patients and 41 control subjects. Questionnaire interview was applied. Blood samples were collected in EDTA tube for ABO blood grouping and DNA extraction. Polymerase Chain Reaction-Restriction Fragment Length Polymorphism (PCR-RFLP) use to detect - 1185A/G polymorphism. The $v W F-1185 A / G$ genotype was the most common in the control and the CHD groups. The frequencies of $v W F-1185$ alleles in the CHD subjects were 0.541 for $A$ and 0.459 for $G$. These frequencies are comparable to those found in the control group which were 0.622 for $A$ and 0.378 for $G$. No statistically significant differences in $v W F-1185$ genotypes were found between the patients and the control groups. Moreover, there was no significant difference between the $v W F-1185$ polymorphism: gender, blood group, hypertension and diabetic in case and controls. However, there was a significant difference between the CHD: age, physical activity and education. To our knowledge, this is the first study in Gaza Strip investigating the relation between $\nu W F-1185 \mathrm{~A} / G$ polymorphism and CHD. Further investigations are needed to link other genetic factors to CHD.
\end{abstract}

Keywords: von Willebrand Factor Gene, Coronary Heart Disease, PCR-Restriction Fragment Length Polymorphism (PCR-RFLP)

\section{Introduction}

von Willebrand factor (vWF) is a large adhesive glycoprotein synthesized by endothelial cells and megakaryocytes that circulates in the plasma as a series of heterogeneous multimers [1-3]. It enhances hemostasis and thrombosis as an important cofactor in platelet adhesion and aggregation, and acts as the carrier protein for coagulation factor VIII [4]. The $v W F$ gene spans $\sim 178 \mathrm{~kb}$ on short arm of chromosome 12 and includes 52 exons. The first 17 exons encode the signal peptide and propeptide in the subsequent protein. The mature vWF subunit corresponds to exons 18to52, which finally undergoes multimerization. Exon 18 encodes the first 51 amino acids of vWF D' domain which is involved in VWF multimerisation and binding of factor VIII. [5]. Exon 18 has the highest frequency of mutation per nucleotide among the 52 exons of the vWF gene (Figure 1).

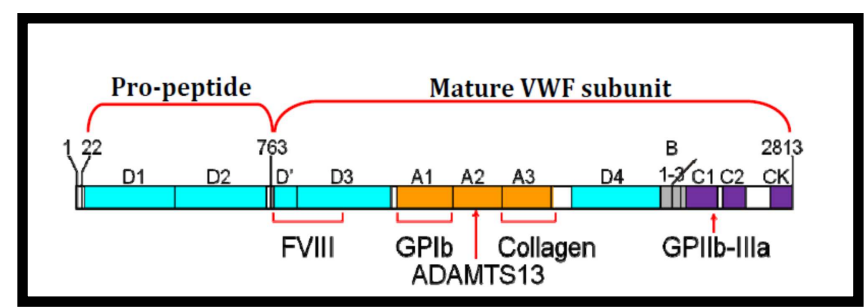

Figure 1. The human $v W F$ protein [6]. 
Most studies have focused on exon 18 and 28, as these regions encode VWF protein domains with important hemostatic functions. The largest exon of $v W F$ gene is exon 28 containing 1379 bases that encode for the A1, A2 and A3 domains of the protein [2]. Genetic analysis of exon 28 on chromosome 12 is conducted by using two or more sequencing reactions with specific primers to cover the whole exon that spans $1.37 \mathrm{~kb}$ [7]. The mutations in exon 28 affect mostly the A1, A2 and A3 domains, as they result in different functional and qualitative abnormalities in vWF [8]. Plasma levels of vWF are not only influenced by nongenetic factors such as hormones and inflammation but are also strongly heritable, with estimates of heritability ranging from 53\%$75 \%[9,10]$. As genetic susceptibility is an important risk factor for Coronary heart disease (CHD) [11, 12], several candidate studies have addressed whether single nucleotide polymorphisms (SNPs) in the $v W F$ gene determine vWF levels and subsequently contribute to the genetic susceptibility for CHD.

Because the vWF promoter region is involved in the regulation of gene transcription and is therefore expected to be a determinant of vWF plasma levels, most studies have focused on SNPs in the promoter region of the $v W F$ gene. Besides the $v W F$ gene, it is well established that other gene loci exert major quantitative effects on vWF plasma levels. The most important of these loci has been shown to be the ABO blood group locus on chromosome 9q34 [13, 14]. People with inherited deficiencies of vWF may suffer a bleeding disorder, von Willebrand disease (vWD), while substantially increased levels are associated with thrombotic disorders [15]. The physiological functions of the protein have led to suggestions that increased circulating concentrations of vWF might be relevant to CHD.

Adult and geriatrics are most vulnerable to risk of CHD and need more monitoring care to prevent the development of CHD. Socioeconomic changes in our region particularly in Gaza strip lead to major change in life style towards sedentary life style and increase the incidence and morbidity of CHD all of these would increase the costs of treatment and rehabilitation identify opportunities for improving the case status of coronary heart patients.

\section{Methodology}

\subsection{Study Population}

This study is a retrospective case-control study in which $v W F$ genotyping and blood group were performed on 126 individuals who were randomly selected. Eighty five subjects (35 female and 50 male) with coronary heart disease recruited from Nasser and Ashifa Hospitals, and forty one normal subjects were included in this study (12 female and 29 male).

\subsection{Sample Collection}

Blood collected with an EDTA tubes. Routinely ABO grouping was carried out at room temperature by rapid slide test. Forward blood group was detected for all study population by using commercial anti $\mathrm{A}$ and anti $\mathrm{B}$ antibodies. For determination of $\mathrm{A}, \mathrm{B}, \mathrm{O}$ and $\mathrm{AB}$ blood groups, a drop of blood was mixed with antisera, and agglutination was observed within one minutes. Then the EDTA sample kept at $4^{\circ} \mathrm{C}$ was used within $24 \mathrm{~h}$ for DNA extraction and subsequent PCR analysis.

\subsection{Data Analysis}

The data was enter, stored and analyzed by personal computer using the statistical package for Social Sciences (SPSS) version 16.0. Independent- Samples T-test, Chi square test and Odd's Ratio (OR) use to compare between the two groups of this study. $\mathrm{P}$ value $<0.05$ were considered statistically significant.

\subsection{Genotyping of $V W F-1185 A / G$}

\subsubsection{DNA Extraction}

Genomic DNA was extracted from blood samples using Wizard DNA extraction kit (Promega, USA) following the manufacturer's instructions from fresh EDTA whole blood cells.

\subsubsection{PCR Amplification of the VWF $-1185 \mathrm{~A} / \mathrm{G}$}

PCR was performed using the primers described by Bitonda et al to detect $-1185 \mathrm{~A} / \mathrm{G}$ polymorphism in the $5^{\prime}$ regulatory region of the $v W F$ gene for all of the 2 groups (Case and Control) [16]. A475bp fragment was amplified from genomic extracted DNA using the following oligonucleotide primers:

forward: 5'ATAAGAGCTGGAAGTGGAAA3' and reverse: 5'AACCTCCTCCCTTCCCACATA3'

$3 \mu \mathrm{l}(\sim 150 \mathrm{ng})$ of prepared DNA template was added to 20 $\mu 1$ master mix (Promega, USA), and $2.0 \mu \mathrm{l}$ of each primer (5 pmol) in $0.2 \mathrm{ml}$ thin walled microfuge tube. PCR was performed in a thermal cycler (Biometra, Germany).

The cycling conditions were: an initial denaturation for 7 min at $95^{\circ} \mathrm{C}$, followed by 35 cycles of $60 \mathrm{~s}$ at $94^{\circ} \mathrm{C}, 30 \mathrm{~s}$ at $51^{\circ} \mathrm{C}, 30 \mathrm{~s}$ at $72^{\circ} \mathrm{C}$ and an additional $10 \mathrm{~min}$ at $72^{\circ} \mathrm{C}$ for final extension. The quality of the isolated DNA was determined by running $5 \mu \mathrm{l}$ of each sample on ethidium bromide stained $1.0 \%$ agarose gels and the DNA was visualized on a short wave U.V. transilluminator.

\subsubsection{Restriction Fragment Length Polymorphism Analysis}

Genotyping for $v W F$ was performed by digesting the PCR product with restriction enzymes (BstUI) and separation of the resulting DNA fragments on 3\% agarose gels. For RFLP analysis the following mixtures were prepared in clean two $0.2 \mathrm{ml}$ microfuge tubes.

For RFLP analysis, a mixture of: $10 \mu \mathrm{L}$ PCR product, nuclease-free water $18 \mu \mathrm{L}, 2 \mu \mathrm{L}$ of $10 \mathrm{X}$ Buffer and $1 \mu \mathrm{L}$ of BstUI $(500 \mathrm{U} / \mathrm{ml})$ added in a clean $0.2 \mathrm{ml}$ microfuge tube. The mixture had been mixed gently and spin down for a few seconds. The contents were incubated at $37^{\circ} \mathrm{C}$ for 2 hours. The digests were resolved on $3 \%$ ethidium bromide stained agarose gels and the results were documented by photography.

Digestion of the fragment with BstUI yielded an 
undigested band of $475 \mathrm{bp}$ from the $-1185 \mathrm{~A}$ allele or fragments of 279 and $196 \mathrm{bp}$ with the $1185 \mathrm{G}$ allele.

\section{Results}

\subsection{Study Population}

The study population consisted of 126 samples (85 case, 41 control). The mean age of subjects was $54.04 \pm 11.07$. The percentage of males was $62.7 \%$ while that of females was $37.3 \%$.

$67.5 \%$ of the participants were non-smokers and $32.5 \%$ were smokers. $64.3 \%$ of the study population were nonhypertensive subjects, while $35.7 \%$ of them were hypertensive. On the other hand, $73 \%$ of the study population was non diabetic subjects. Some of the cases were hypertensive or diabetic. Most of the subjects had no family history of coronary heart diseases.

\subsection{CHD, Gender and Age}

The results revealed that there is no statistically significant correlation between CHD and gender of the subjects ( $p$ value $=0.24)$, where more than half of cases $(58.82 \%)$ were males and most of the controls $(70.73 \%)$ were males.

There is a statistically significant difference between the means of age of cases and controls $(p$-value $=0.009)$ where the mean age of cases was 55.82 years, while that of the controls was 50.34 .

\subsection{CHD, Physical Activity and Education}

Our findings showed that there is statistical significance in physical activity (all activity at work and leisure) among study groups p-value: 0.000 . Sedentary people have about twice the risk of developing CHD, compared to active people (OR: 1.8, CI: 1.5-2.2). In the overall sample, there were substantial differences in the educated between case and control groups with p-value: 0.001 . On the other hand, there was statistically differences between gender and education among the subjects (p-value: 0.049) with low levels of education among women.

\subsection{CHD and Blood Group}

As shown in Table 1, the incidence of CHD in individuals

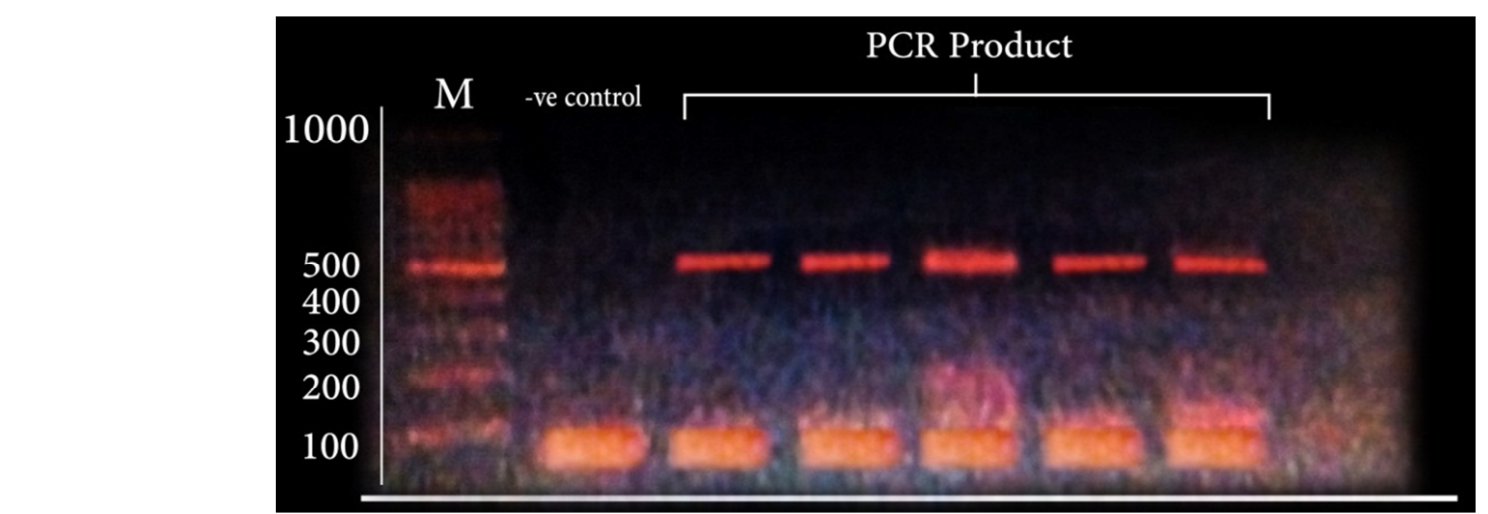

Figure 2. A photograph of vWF amplification product. Lane 1: 100bp ladder, lane 2 negative control and the rest of lanes show the 475 bp vWF PCR product. with blood group $\mathrm{A}$ is $41.17 \%$, while this incidence is $14.11 \%$ in individuals with blood group B, $5.88 \%$ in blood group $\mathrm{AB}$, and $38.82 \%$ in blood group $\mathrm{O}$. By comparison, the incidence of blood groups $\mathrm{A}, \mathrm{B}, \mathrm{AB}$, and $\mathrm{O}$ in healthy subjects in the control group were $39.02 \%, 17.07 \%, 4.87 \%$, and $39.02 \%$, respectively.

Table 1. Frequency of ABO blood groups in CHD patients and controls.

\begin{tabular}{lllllllll}
\hline Blood & \multicolumn{2}{l}{ Control } & Case & \multicolumn{3}{l}{ Total } & P- \\
\cline { 2 - 7 } Group & No. & $\%$ & No. & $\%$ & No. & $\%$ & value \\
\hline A & 16 & 39.02 & 35 & 41.17 & 51 & 40.50 & \\
B & 7 & 17.07 & 12 & 14.11 & 19 & 15.10 & \\
AB & 2 & 4.87 & 5 & 5.88 & 7 & 5.60 & 0.970 \\
O & 16 & 39.02 & 33 & 38.82 & 49 & 36.90 & \\
Total & 41 & 100 & 85 & 100 & 126 & 100 & \\
\hline
\end{tabular}

We also found that $45.5 \%$ of blood group $\mathrm{O}$ population had CHD in their family history. With regard to smoking and family history, differences were not significant when we compared O blood group with Non-O blood group. (Table 2)

Table 2. Distribution of different variables among $O O$ and Non-OO blood groups in CHD patients.

\begin{tabular}{llllll}
\hline Variable & \multicolumn{3}{l}{ CHD patients } & \multicolumn{2}{l}{ P-value } \\
\hline & \multicolumn{3}{l}{$\boldsymbol{O}$} & \multicolumn{3}{l}{ Non- $\boldsymbol{O O}$} \\
\hline & No & \% & No & \% & \\
\hline Smoking & 13 & 40.6 & 19 & 59.4 & 0.79 \\
Family history & 10 & 45.5 & 12 & 54.5 & 0.46 \\
History of CHD & 12 & 37.5 & 20 & 62.5 & 0.85 \\
Diabetes & 13 & 38.2 & 21 & 61.8 & 0.92 \\
Hypertension & 15 & 33.3 & 30 & 66.7 & 0.27 \\
\hline
\end{tabular}

\subsection{PCR Results}

\section{PCR amplification of the VWF $-1185 \mathrm{~A} / \mathrm{G}$}

The PCR product generated from the $v W F-1185 A / G$ polymorphism should yield a 475 bp-long double-stranded DNA fragment. A negative control (with water instead of the DNA template) was included in each reaction. The size of the amplicon was estimated by comparing it with a DNA molecular size marker (100 bp ladder DNA) run on the same gel. A represented photograph of $v W F$ PCR amplification product is illustrated in Figure 2 below. Lane 1 in the figure shows the $100 \mathrm{bp}$ DNA marker, lane 2 contains a negative control and the other lanes show the 475 bp $v W F$ amplicon. 


\subsection{RFLP Result and Genotype Frequencies}

Figure 3. Illustrates a representative $v W F$ genotyping by BstUI digestion of the $475 \mathrm{bp}$ amplified fragment.

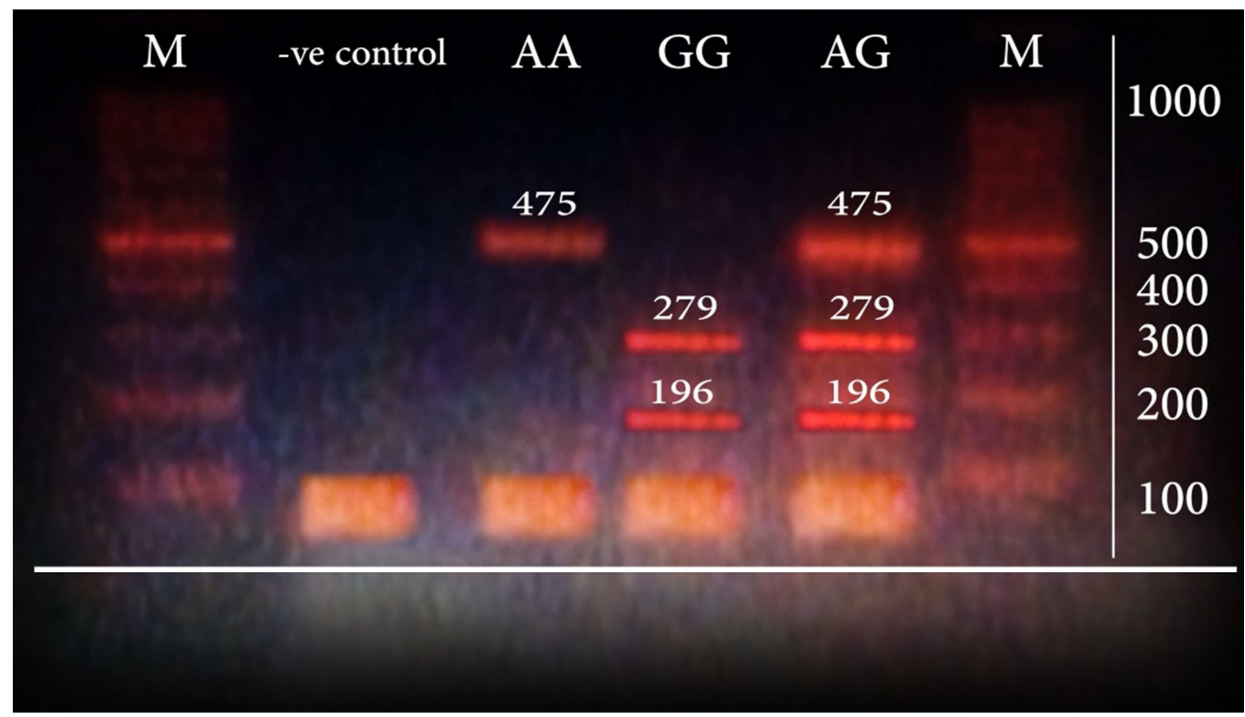

Figure 3. A representative photograph of BstUI digestion of the $v W F 475 \mathrm{bp}$ amplified fragment. M indicates the 100 bp size marker. The digests were run on ethidium bromide stained 3\% agarose gel, $A A=475 \mathrm{bp}, G G=279,196 \mathrm{bp}, A G=475,279,196 \mathrm{bp}$.

The $v W F-1185 A / G$ allele frequencies in the control group were $62.20 \%$ for the $A$ allele and $37.80 \%$ for the $G$ allele. The frequencies in the CHD group were $54.12 \%$ and $45.88 \%$ for the $A$ and $G$ alleles respectively (Table 3 ).

\subsection{Distribution of Subjects According to vWF Genotypes}

The distribution of the subjects according to $v W F$ genotypes were as follows, $36.5 \% A / A, 40.5 \% A / G$, and $23 \%$ $G / G$.

Table 3. Frequency of $v W F$ alleles among the case and the control groups.

\begin{tabular}{|c|c|c|c|c|c|}
\hline \multirow{2}{*}{ Alleles } & \multicolumn{2}{|c|}{ CHD group } & \multicolumn{2}{|c|}{ Control group } & \multirow{2}{*}{$P$-value } \\
\hline & No. & $\%$ & No. & $\%$ & \\
\hline$A$ & 92 & 54.12 & 51 & 62.20 & \\
\hline$G$ & 78 & 45.88 & 31 & 37.80 & 0.226 \\
\hline Total & 170 & 100 & 82 & 100 & \\
\hline
\end{tabular}

\subsection{Relationship Between CHD and vWF Gene Polymorphism}

The results showed that there was no statistically significant relation between CHD and $v W F$ gene polymorphism ( $\mathrm{p}$-value $=0.481$ ), where the most frequent genotype among case and control were $A / G: 42.2 \%$ and $A / A$ : $43.9 \%$ respectively, as shown in Table 4 .

Table 4. Distribution of the vWF genotypes among the cases and the control groups.

\begin{tabular}{llllllll}
\hline \multirow{2}{*}{ Genotype } & \multicolumn{1}{l}{ Case } & \multicolumn{5}{c}{ Control } & \multicolumn{2}{c}{ Total } & \multirow{2}{*}{ P-value } \\
\cline { 2 - 6 } & No. & $\mathbf{\%}$ & No. & \% & No. & \% & \\
\hline$A / A$ & 28 & 32.9 & 18 & 43.9 & 46 & 36.5 & \\
$A / G$ & 36 & 42.4 & 15 & 36.6 & 51 & 40.5 & \multirow{2}{*}{0.481} \\
$G / G$ & 21 & 24.7 & 8 & 19.5 & 29 & 23.0 & \\
Total & 85 & 100 & 41 & 100 & 126 & 100 & \\
\hline
\end{tabular}

\subsection{Relationship Between vWF Genotype, Gender and Blood Group}

The results showed that there is no statistically significant relation between $v W F$ genotype and gender ( $\mathrm{p}$-value $=0.729)$, Table 5.

Table 5. Relationship between $v W F$ gene and Gender.

\begin{tabular}{lllll}
\hline Genotype & Male & Female & Total & P-value \\
\hline$A / A$ & 28 & 18 & 46 & \\
& $(35.44 \%)$ & $(38.3 \%)$ & & \\
$A / G$ & 31 & 20 & 51 & 0.729 \\
& $(39.25 \%)$ & $(42.55 \%)$ & & \\
$G / G$ & 20 & 9 & 29 & \\
Total & $(25.31 \%)$ & $(19.15 \%)$ & 126 & \\
\hline
\end{tabular}

The data indicated in table 6 show that there is no statistically significant difference between the distribution of $\nu W F$ genotypes among $O O$ and Non-OO blood group in both study groups. As shown in the table the most frequent $v W F$ genotypes in Non- $O O$ blood group were $A / G(40.38 \%)$ and $A / A(44.0 \%)$ in case and control groups respectively.

Table 6. Relationship between $v W F$ genotype and blood group.

\begin{tabular}{llllll}
\hline \multirow{2}{*}{ Genotype } & Case & \multicolumn{3}{c}{ Control } & \multirow{2}{*}{ P-value } \\
\cline { 2 - 5 } & $\boldsymbol{O O}$ & Non-OO & $\boldsymbol{O O}$ & Non-OO & \\
\hline \multirow{2}{*}{$A / A$} & 9 & 19 & 7 & 11 & \\
& $27.27 \%$ & $36.54 \%$ & $43.75 \%$ & $44.0 \%$ & \\
$A / G$ & 15 & 21 & 6 & 9 & \\
& $45.46 \%$ & $40.38 \%$ & $37.50 \%$ & $36.0 \%$ & \multirow{2}{*}{0.75} \\
$G / G$ & 9 & 12 & 3 & 5 & \\
& $27.27 \%$ & 23.08 & $18.75 \%$ & $20.0 \%$ & \\
\multirow{2}{*}{ Total } & 33 & 52 & 16 & 25 & \\
\hline
\end{tabular}




\subsection{0. vWF Genotype, Hypertension and Diabetes}

The results of our study indicated that the most $v W F$ genotype frequency among hypertensive patient in case group was $A / G: 42.2 \%$, while the most frequent allele was $G$ allele: $52.2 \%$. The $v W F$ genotype and allele frequencies among diabetic patients: $A / A, A / G$ and $G / G$ were: $26.5 \%$, $47.0 \%$ and $26.5 \%$ respectively. Table 7

Table 7. $v W F$ genotype and allele frequencies among hypertensive and diabetic patients.

\begin{tabular}{lll}
\hline Genotype & Hypertensive patients & Diabetic patients \\
\hline$A / A$ & 12 & 9 \\
& $26.67 \%$ & $26.5 \%$ \\
$A / G$ & 19 & 16 \\
& $42.22 \%$ & $47.0 \%$ \\
$G / G$ & 14 & 9 \\
Total & $31.11 \%$ & $26.5 \%$ \\
$P$-value & 45 & 34 \\
Allele & 0.25 & 0.58 \\
$A$ & 43 & \\
& $47.8 \%$ & 34 \\
$G$ & 47 & $50 \%$ \\
Total & $52.2 \%$ & 34 \\
\hline
\end{tabular}

\section{Discussion}

Coronary Heart disease remains the leading cause of death in the world as well as in the Palestinian territories. Approximately $80 \%$ of all CHD related deaths occur in lowand middle-income countries [17]. Despite that, the published data on the disease were limited in the Gaza strip and most of information emerged from annual reports produced by the Palestinian Ministry of Health. Recently two studies investigated the traditional risk factors associated with CHD in Gaza strip [18, 19]. However, no previous study investigated $v W F$ gene polymorphism in CHD patients. Therefore, this is the first study to assess the frequencies of the $-1185 A / G$ genotypes and alleles in Gaza strip with CHD.

\subsection{Relation Between CHD and Gender}

There is a marked difference in CHD risk between sexes [20]. Among middle-aged people, CHD is 2 to 5 times more common in men than in women, and this sex ratio varies between populations [21]. CHD incidence among men was $\approx 3$-fold and mortality $\approx 5$-fold greater than in women. The evidence of gender-related variables may help in explaining health-related sex differences includes the higher prevalence of CHD in younger men than in women [22]. The reason why men are at an increased risk may partly be explained by their gender-based propensity to engage in risk taking behaviors such as smoking, eating more red meat and fewer fruits and vegetables, and exposure to physical hazards [23]. It was also a popular premise that men were harmed by the stresses of the workplace; women were apparently protected by being at home relaxing with the children and the washing up.

During the fetal period, male and female phenotypes are developed through the action of sex hormones [24]. The decrease in estrogen production after menopause changes the female lipid metabolism toward a more atherogenic form by decreasing the HDL cholesterol level and by increasing LDL and total cholesterol, triglyceride, and lipoprotein levels. Among women, estrogen is the predominant sex hormone. Estrogen may have cardioprotective effects [25] through glucose metabolism and the hemostatic system, and it may also have a direct effect on endothelial cell function [26, 27]. In our study we showed that the percentage of CHD in males is higher than that in females may be due to the advanced age of the women (postmenopausal).

\subsection{Relation Between CHD and Age}

Our results revealed that advanced age increases the risk of CHD where the main age of cases was 55.82 years of cases. These results agreed with the fact that advancing age is one risk factor used as alternate for atherosclerotic plaque burden. With aging there is a gradual accumulation of coronary plaques. This accounts for the increasing risk of CHD with advancing age [28].

\subsection{Relation Between CHD and Physical Activity}

The present study found that $41.2 \%$ of cases are not physically active. As we noted from our results, there was good agreement with the evidence that physical inactivity is one of the major modifiable risk factors for CHD. Over the past 40 years, evidence has accumulated on the role of physical activity in preventing and treating CHD [29], and show that physically inactive people have about twice the risk of developing or dying from $\mathrm{CHD}$, compared to active people that we approved in our study (OR: 1.8, CI: 1.5-2.2). The benefits of physical activity include [30] improvement in myocardial contraction and its electrical stability, and an increase in stroke volume at rest and during exercise, leading to a higher maximal cardiac output. Heart rate is decreased at rest, and at any given level of submaximal cardiac output. Endothelial function is improved, leading to better flowmediated dilatation. In addition, the diameter and dilatory capacity of coronary arteries are increased, also has effects on the tendency of blood to clot. Changes include reduced platelet aggregation and increased fibrinolytic activity. In addition, regular physical activity lowers inflammatory factors such as plasma fibrinogen concentrations, C-reactive protein and white cell count. There is limited data, however, describing physical activity and CHD risk factors in Palestinian adult populations.

\subsection{Relation Between CHD and Education}

This study demonstrated that there was strong negative relationship between education level and risk of CHD, and this association was stronger in women participated in this study.

Low educational attainment, a marker of low socioeconomic status, has consistently been associated with an increased risk of cardiovascular morbidity and mortality 
$[31,32]$ in men and even more strongly in women. However, the mechanisms underlying this association are not well understood. A theoretical model for this social gradient is that low educational attainment may be associated with increased levels of psychosocial stress. The combination of low education and psychosocial stress may result in unhealthy lifestyle patterns and pathogenic physiological reactions, which lead to CHD [33]. Studies often show reductions in effect size of education with CHD after adjustment for conventional CHD risk factors such as blood pressure, diabetes, and obesity, suggesting these may be part of the explanatory pathway [34, 35]. Education is typically associated with protective health behaviors such as fruit/vegetable consumption [36], and non-smoking [37], suggesting these may also be mechanisms.

\subsection{Relation Between CHD and Blood Group}

Our study demonstrated that $61.18 \%$ of case and $60.98 \%$ of control were non- O blood type. Of Non- O case $59.4 \%$, $54.5 \%, 61.8 \%$ and $66.7 \%$ were smoking, had CHD family history, Diabetes and Hypertension respectively.

The association between a blood group and cardiovascular diseases has been known for many years, its complex nature has not been fully elucidated yet. The majority of the studies have reported associations between the $\mathrm{ABO}$ group and thrombosis, indicating that non- $\mathrm{O}$ blood groups carry a higher risk of MI, venous thromboembolism, and cardiovascular diseases than the O blood group. The extent of these associations is still unclear. Most researchers link a non -O blood group with higher vWF levels associated with a higher risk of cardiovascular disease in these patients [13].

$\mathrm{Wu}$ et al. published a meta-analysis of ABO blood groups with reference to cardiovascular disease. It included 22 studies on MI, 9 of which reported that individuals with non$\mathrm{O}$ groups had a significantly higher risk of MI and 1 reported a reduced risk in this group of patients [38]. Dentali et al conducted a systematic literature review and meta-analysis on the relationship between the $\mathrm{ABO}$ blood group and hemorrhage [39]. Interestingly, they found that group O was more frequent in the group of patients with bleeding that in controls (odds ratio, 1.33; 95\% confidence interval, 1.25 1.42; $P<0.001)$. In our study, we did not observe similar differences.

\subsection{Genotype Frequencies of vWF in Gaza Strip}

Recently, four single nucleotide polymorphisms (SNPs) in the 5'-regulatory region of the $v W F$ gene have been associated with plasma VWF levels in a normal population $[40,41]$. These polymorphisms were in strong linkage disequilibrium and segregated in two distinct haplotypes. In one of these SNPs, the $-1185 A / G$ polymorphism, $A A$ homozygotes were significantly associated with the highest levels of vWF, $G G$ homozygotes showed the lowest levels, and heterozygotes intermediate levels [40].

The observed genotype frequencies were in HardyWeinberg equilibrium for both groups. According to the results obtained from PCR-RFLP the $-1185 A / G \quad v W F$ polymorphism allele frequencies in Gaza Strip were: $54.12 \%$ for $A$ allele and $45.88 \%$ for $G$ allele in CHD patients, $62.2 \%$ and $37.8 \%$ in control individuals for $A$ and $G$ alleles respectively. No significant differences were detected in allele or genotype frequencies between patients and controls $(\mathrm{p}=0.226)$.

A study conducted in Brazil showed that the frequencies of the $-1185 G$ polymorphism in type $1 \mathrm{vWD}$ patient was $63.4 \%$ in patients and $57.4 \%$ in control individuals $(p=0.29)$. It was significantly different from those previously reported in Swedish individuals ( $\mathrm{G}$ allele $=71 \%, \mathrm{p}<0.001)$ [42], from those described by Keightley et al. (1999) for predominantly Caucasian Canadian subjects $(\mathrm{G}$ allele $=64 \%, \mathrm{p}=0.014)$, and from those described for Dutch subjects $(\mathrm{G}$ allele $=64 \%$; $\mathrm{p}=0.011)[43]$.

\subsection{Relationship Between CHD and vWF Gene Polymorphism}

Notably, the results show that overall, $v W F$ gene polymorphism at the $-1185 \mathrm{~A} / \mathrm{G}$ site is do not differ significantly between patients and controls, indicating that there is no association between this polymorphism and CHD.

This finding may be caused by the limited sample size and needs to be evaluated in a larger cohort.

Tompkins et al. analyzed patients with unstable angina and ABO-matched and age-matched control subjects. The analysis of the three vWF gene regulatory sequence polymorphisms, including the $-1185 A / G$ polymorphism, showed no significant difference between the two groups, but high levels of plasma vWF were associated with unstable angina [44].

Di Bitondo et al. investigated the $-1185 \mathrm{~A} / \mathrm{G}$ and-1051G/A polymorphisms and the risk of myocardial infarction in a case-control study and found no association between them [45]. The findings of the present study indicate that the $1185 \mathrm{~A} / \mathrm{G} v W F$ gene polymorphism is not an independent risk factor for $\mathrm{CHD}$ in the Palestinian population. Our data therefore are not consistent with the hypothesis that the $1185 \mathrm{~A} / \mathrm{G} v W F$ gene polymorphism is related to CHD.

\subsection{Relationship Between vWF Genotype and Blood Group}

It has long been known that the ABO blood type has a profound influence on hemostasis, being a major determinant of the vWF and, consequently, of factor VIII plasma levels [46].

vWF levels are approximately $25 \%$ higher in individuals who have a blood group other than $\mathrm{O}$ [47]. The presence of $\mathrm{ABH}$ structures in vWF N-linked oligosaccharides provides the molecular basis for the ABO regulation of vWF levels [48]. The active ABO A and B glycosyltransferase enzymes, found in the Golgi system of endothelial cells, generate terminal carbohydrate modifications, i.e. A and B antigens, on the existing vWF " $\mathrm{H}$ " oligosaccharides, whereas the enzymatically inactive $\mathrm{ABO} O \mathrm{O}$ protein cannot modify these vWF $\mathrm{H}$ antigens [49]. 
As previously mentioned that $A A$ homozygotes were significantly associated with the highest levels of vWF, the most frequent $v W F$ genotypes in this study among Non-O blood type patients was $A / G: 40.38 \%, A / A 44.0 \%$ was the most frequent genotypes in Non-O blood group healthy individuals ( $\mathrm{p}$-value $=0.75$ )

\section{Conclusion}

The present study focused on detection of $-1185 \mathrm{~A} / \mathrm{G} v W F$ genotypes in Gaza Strip and the relationship between those genotypes and CHD as compared to healthy subjects. The results of this study can be summarized as follows:

- In Gaza Strip, the $A / G$ genotype was the most common in the control and the CHD groups. $A / A$ was the next most common genotypes.

- The frequencies of $1185 \mathrm{~A} / \mathrm{G}$ alleles in the CHD subjects were: 0.5412 for the $A, 0.4588$ for the $G$. These frequencies are comparable to those found in the control group where we obtained: 0.622 for the $A, 0.378$ for the $G$.

- No statistically significant differences in $-1185 \mathrm{~A} / \mathrm{G}$ $v W F$ genotypes were found between the patients and the control groups.

- There is no significant difference between male and female in terms of the $-1185 \mathrm{~A} / \mathrm{G} v W F$ genotypes.

- The results of the study showed that there is a statistically significant difference between the means of age of cases and controls.

- There is statistical significance in physical activity among study groups. Sedentary people have about twice the risk of developing CHD, compared to active people.

- There was strong negative relationship between education level and risk of CHD, and this association was stronger in women participated in this study.

- The most frequent blood group was A in both groups.

- Hypertension, diabetes and CHD family history were most frequent among Non-O blood type in CHD patients.

CHD is still a health problem, particularly in old age, not only in Gaza Strip, but worldwide, so more detailed relevant genes variations analysis is required to clarify genes correlates of coronary heart disease.

\section{References}

[1] Z. Ruggeri, T. Zimmerman, "The complex multimeric composition of factor VIII/vWF", Blood, pp 1140-1143, 1981.

[2] J. Sadler, "Biochemistry and genetics of von Willebrand factor", Annual Review of Biochemistry, 67, pp 395-424, 1998.

[3] Z. Ruggeri, "Structure of von Willebrand factor and its function in platelet adhesion and thrombus formation", Best Practice \& Research Clinical Haematology, pp 257-259, 2001.

[4] G. Lowe, "Haemostatic risk factors for arterial and venous thrombosis in: Poller L, Ludlam CA (ed", Recent advances in blood coagulation Edinburgh, Churchill Livingstone, pp 6996, 1997.

[5] D. Mancuso, E. Tuley, L. Westfield, N. Worrall, B. SheltonInloes, J. Sorace, Y. Alevy, J. Sadler, "Structure of the gene for human von Willebrand factor", Journal of Biological Chemistry, pp 19514-19527, 1989.

[6] T. Canciani, A. Federici, "Clinical and laboratory versus molecular markers for a correct classification of von Willebrand disease", haematologica, 94 (5), pp 610-615.

[7] P. James, D. Lillicrap, "Genetic testing for von Willebrand disease: the Canadian experience", Seminars in Thrombosis and Hemostasis, 32, pp 546-552, 2006.

[8] P. Casana, F. Martinez, S. Haya, A. Tavares, J. Aznar, "New mutations in exon 28 of the von Willebrand factor gene detected in patients with different types of von Willebrand's disease", Haematologica, 86, pp 414-419, 2001.

[9] E. Bladbjerg, M. de Maat, Christensen K, Bathum L, J. Jespersen, J. Hjelmborg, "Genetic influence on thrombotic risk markers in the elderly", Journal Thrombosis Haemostsis, 4 (3), pp 599-607, 2006.

[10] M. Lange, H. Snieder, R. Ariens, T. Spector, P. Grant, "The genetics of haemostasis", Lancet, 357 (9250), pp 101-105, 2001.

[11] J. Souto, L. Almasy, M. Borrell, "Genetic susceptibility to thrombosis and its relationship to physiological risk factors. Genetic analysis of idiopathic thrombophilia", American Journal Human Genetics, pp 1452-1459, 2000.

[12] T. Larsen, H. Sorensen, A. Skytthe, S. Johnsen, J. Vaupel, K. Christensen, "Major genetic susceptibility for venous thromboembolism in men", Epidemiology, pp 328-332, 2003.

[13] J. O'Donnell, M. Lasffan, "The relationship between ABO histo blood group, factor VIII and von Willebrand factor", Transfusion Medicine, pp 343-351, 2001.

[14] P. Jenkins, J. O'Donnell, “ABO blood group determines plasma von Willebrand factor levels: a biologic function after all?, Transfusion, pp 1836-1844, 2006.

[15] A. Fosang, P. Smith,“ To clot or not”, Nature, pp 475-481, 2001.

[16] R. Bitondo, C. Cameron, M. Daly, S. Croft, R. Steeds, K. Channer, N. Samani, D. Lillicrap and P. Winship,“ The 21185 $\mathrm{A} / \mathrm{G}$ and $21051 \mathrm{G} / \mathrm{A}$ dimorphisms in the von Willebrand factor gene promoter and risk of myocardial Infarction", British Journal of Haematology, 115, pp 701-706, 2001.

[17] J. Gersh, S. Karen, M. Bongani and Y. Salim, "The epidemic of cardiovascular disease in the developing world global implications", European Heart Journal, 31 (6), pp 642-650, 2010.

[18] S. Khwaiter, "Risk factors associated with coronary artery disease in Gaza", MSC thesis, IUG of Gaza, Palestine, 2009.

[19] M. Mushtaha, "Risk factors of in coronary artery disease patients undergoing cardiac catheterization in Gaza governorates", British Journal of Medicine \& Medical Research, 5 (1), pp 88-97, 2010.

[20] W. Castelli, "Epidemiology of coronary heart disease: the Framingham B Study", American Journal of Medicine, 76, pp $4-12,1984$ 
[21] R. Jackson, L. Chambless, M. Higgins, K. Kuulasmaa, L. Wijnberg, D. Williams, "Sex difference in ischaemic heart disease mortality and risk factors in 46 communities: an ecologic analysis", Cardiovasc Risk Factors, 7, pp 43-54, 1997.

[22] M. Izadnegahdar, J. Singer, M. Lee, M. Gao, C. Thompson, J. Kopec, "Do younger women fare worse? Sex differences in acute myocardial infarction hospitalization and early mortality rates over ten years", Journal of Womens Health, 23 (1), pp 10-17, 2014.

[23] F. Sozzi, G.. Danzi, L. Foco, M. Ferlini, M. Tubaro, M. Galli, "Myocardial infarction in the young: a sex-based comparison", coronary artery disease, 18 (6), pp 429-431, 2007.

[24] K. Matthews, E. Meilahn, L. Kuller, S. Kelsey, A. Caggiula, R. Wing, "Menopause and risk factors for coronary heart disease", New England Journal of Medicine, 321, pp 641-646, 1989.

[25] C. Bonithon-Kopp, P. Scarabin, B. Darne, A. Malmejak, L. Guize, "Menopause-related changes in lipoproteins and some other cardiovascular risk factors", International Journal of Epidemiology, 19, pp 42-48, 1990.

[26] D. Grady, S. Rubin, D. Petitti, C. Fox, D. Black, B. Ettinger, V. Ernster, S. Cummings, “ Hormone therapy to prevent disease and prolong life in postmenopausal women", Annals of Internal Medicine, 117, pp. 1016-1037, 1992.

[27] E. Shahar, A. Folsom, V. Salomaa, V. Stinson, P. McGovern, T. Shimakawa, L. Chambless, K. Wu, "For the atherosclerosis risk in communities (ARIC) study investigators. relation of hormone replacement therapy to measures of plasma fibrinolytic activity”, Circulation, 93, pp 1970-1975, 1996.

[28] V. Perova, E. Davis, S. Tao, A. Pajak, Y. Stein, G. Broda, H. Tyroler, "Multi-country comparison of plasma lipid relationship to years of schooling in men and women", International Journal of Epidemiology, 30, pp 371-379, 2001.

[29] V. Press, I. Freestone, C. George, "Physical activity: the evidence of benefit in the prevention of coronary heart disease", Quarterly journal of medicine, 96, pp 245-251, 2003.

[30] C. Bouchard, "Physical activity and prevention of cardiovascular diseases: potential mechanisms. physical activity and cardiovascular health", Champaign IL, Human Kinetics, pp 48-56, 1997.

[31] G. Kaplan, J. Keil, "Socioeconomic factors and cardiovascular disease: a review of literature", Circulation, 88, pp 1973-1998, 1993.

[32] C. Lenfant,“ Conference on socioeconomic status and cardiovascular health and disease", Circulation, 94, pp 20412044, 1996

[33] S. Wamala, K. Orth-Gomer, "Interfaces of human biology and social organization: challenges for future research. In: Inequality in Health-A Swedish perspective: contributions from Swedish researchers in the social, behavioral and medical sciences for a national research program on inequality in health", Swedish Social Research Council, pp 113-130, 1998.

[34] M. Albert, R. Glynn, J. Buring, P. Ridker, "Impact of traditional and novel risk factors on the relationship between socioeconomic status and incident cardiovascular events", Circulation, 12, pp 2619-2645, 2006.
[35] E. Loucks, J. Lynch, L. Pilote, R. Fuhrer, N. Almeida, H. Richard, G. Agha, J. Murabito, E. Benjamin, "Life-course socioeconomic position and incidence of coronary heart disease. The Framingham offspring study", American Journal of Epidemiology, 169 (7), pp 829-836, 2009.

[36] K. Giskes, M. Avendano, J. Brug, A. Kunst, "A systematic review of studies on socioeconomic inequalities in dietary intakes associated with weight gain and overweight/obesity conducted among European adults", Obesity reviews, 11 (6), pp 413-429, 2010.

[37] S. Gilman, L. Martin, D. Abrams, I. Kawachi, L. Kubzansky, E. Loucks, R. Rende, R. Rudd, S. Buka," Educational attainment and cigarette smoking: a causal association", International Journal of Epidemiology, 37 (3), pp 615-624, 2008.

[38] O. Wu, N. Bayoumi, M. Vickers, P. Clark, “ABO (H) blood groups and vascular disease: asystematic review and metaanalysis", Journal of Thrombosis and Haemostasis, 6, pp 6269,2008 .

[39] F. Dentali, A. Sironi, W. Ageno, C. Bonfanti, S. Crestani, F. Frattini, L. Steidl, M. Franchini, "Relationship between ABO blood group and hemorrhage: a systematic literature review and meta-analysis", Semin Thromb Hemost, 39, pp 72-82, 2013.

[40] A. Keightley, Y. Lam, J. Brady, C. Cameron, D. Lillicrap, "Variation at the von Willebrand factor (VWF) gene locus is associated with plasma VWF: Ag levels: identification of three novel single nucleotide polymorphisms in the VWF gene promoter", Blood, 93, pp 4277-4283, 1999.

[41] P. Harvey, A. Keightley, Y. Lam, C. Cameron, D. Lillicrap, "A single nucleotide polymorphism at nucleotide -1793 in the von Willebrand factor (VWF) regulatory region is associated with plasma VWF: Ag levels", British Journal of Haematology, 109, pp 349-353, 2000.

[42] Z. Zhang, M. Blombäck, N. Egberg, G. Falk, M. Anvret, "Characterization of the von Willebrand factor gene (VWF) in von Willebrand disease type III patients from 24 families of Swedish and Finnish origin", Genomics, 21, pp 188-193, 1994.

[43] P. Kamphuisen, J. Eikenboom, F. Rosendaal, T. Koster, A. Blann, H. Vos, R. Bertina, "High factor VIII antigen levels increase the risk of venous thrombosis but are not associated with polymorphisms in the von Willebrand factor and factor VIII gene", British Journal of Haematology, 115, pp 156-158, 2001.

[44] K. Tompkins, C. Cameron, J. Brady, S. Raj, A. Keightley, D. Lillicrap, "Polymorphisms in the glycoprotein Ib $\alpha, \alpha 2$ integrin and von Willebrand factor genes: possible implications in platelet adhesion and acute coronary events", Blood, 94-165, 1999.

[45] R. Di Bitondo, C. Cameron, M. Daly, S. Croft, R. Steeds, K. Channer, N. Samani, D. Lillicrap, P. Winship, "The -1185 A/G and $-1051 \mathrm{G} / \mathrm{A}$ dimorphisms in the von Willebrand factor gene promoter and risk of myocardial infarction", British Journal of Haematology, 115, pp 701-706, 2001.

[46] A. Preston, A. Barr,“ The plasma concentration of factor VIII in the normal population”, British Journal of Haematology, 10, pp 238-283, 1964. 
[47] J. Gill, J. Endres-Brooks, P. Bauer, W. Marks, R. Montgomery, "The effect of ABO blood group on the diagnosis of von Willebrand disease", Blood, 69, pp 1691$1696,1987$.

[48] T. Matsui, K. Titani, T. Mizuochi, "Structures of the asparagine linked oligosaccharide chains of human von Willebrand factor Occurrence of blood group A, B, and H (O) structures", Journal of Biological Chemistry, 267, pp 87238731, 1992.

[49] J. Sodetz, S. Pizzo, P. McKee, "Relationship of sialic acid to function and in vivo survival of human factor VIII/von Willebrand factor protein", Journal of Biological Chemistry, 252, pp 5538-46, 1977. 